\title{
Addendum
}

\section{English medium instruction: Global views and countries in focus - ADDENDUM}

\section{Ernesto Macaro}

DOI: https://doi.org/10.1017/S0261444816000380, Published by Cambridge University Press, 18 January 2017.

Dr Stephen Evans (Hong Kong Polytechnic University) also contributed to the symposium. Unfortunately Stephen fell seriously ill soon after and was unable to write up his part of the proceedings. We have recently received the very sad news that Stephen has passed away. The field of Applied Linguistics has lost a meticulous scholar and a wonderful colleague.

\section{Reference}

Macaro, E. (2017). English medium instruction: Global views and countries in focus: Introduction to the symposium held at the Department of Education, University of Oxford on Wednesday 4 November 2015. Language Teaching 1-18. doi:10.1017/S0261444816000380 